\title{
DOAÇÃO DE ÓRGÃOS E RECUSA FAMILIAR: UMA PROPOSTA DE INTERVENÇÃO
}

\author{
Catarina Piolla Graf', Orlando de Castro e Silva Junior ${ }^{2}$
}

\section{RESUMO}

O artigo tem como objetivo oferecer nova alternativa à questão da doação de órgãos. Cerca de $42 \%$ das doações que não são efetivadas têm como causa a negativa familiar, e isso se deve, em grande parte, ao desconhecimento em relação a conceitos como morte encefálica, processo de doação de órgãos e como funciona a lista de receptores. Sugere-se a inserção de aulas sobre esses temas durante o Curso de Formação de Condutores (CFC), sendo o treinamento aos instrutores oferecido por universidades e unidades públicas de saúde, uma vez que essa medida seria de baixo custo de implantação. A proposta será levada a câmara de vereadores para ser elaborada como projeto de lei e votada, para posteriormente ser colocada em prática na cidade de Ribeirão Preto, com apoio da Faculdade de Medicina de Ribeirão Preto (FMRP) e da Liga Acadêmica de Cirurgia e Transplante da FMRP, lembrando a importância de instituições acadêmicas no processo de doação.

Descritores: Obtenção de Tecidos e Órgãos, Transplante, Doadores de Tecidos, Educação Médica, Legislação como Assunto.

\footnotetext{
Instituição:

${ }^{1}$ Curso de Medicina da Faculdade de Medicina de Ribeirão Preto da Universidade de São Paulo. Ribeirão Preto/SP- Brasil

2 Departamento de Cirurgia e Anatomia e Divisão de Cirurgia Digestiva da Faculdade de Medicina de Ribeirão Preto da Universidade de São Paulo. Ribeirão Preto/SP - Brasil

Correspondência:

Catarina Piolla Graf HCFMRPUSP

Av. Bandeirantes, 3900 - Monte Alegre (Campus). Departamento de Cirurgia e Anatomia- $9^{\circ}$ andar. CEP: 14048- 900 - Ribeirão Preto/SP Tel.: (16) 3602-1000

E-mail: catarina.graf@usp.br
}

\section{INTRODUÇÃO}

Existem muitos gargalos que impedem o funcionamento correto da cadeia entre doação e transplante de órgãos no Brasil. A demora no processo até a liberação do corpo, a incerteza sobre a vontade do familiar em vida, a dificuldade de entender o conceito de morte encefálica, a desconfiança em relação ao sistema; todos esses fatores têm em comum a quase inexistência de programas de educação continuada que abordem essas questões, falhando em estimular o diálogo sobre o assunto, levando, invariavelmente, à negativa familiar, que, em 2017, representou $42 \%$ dos casos de não concretização das doações, como mostra a figura $1 .^{1}$ 
Figura 1 - Causas de Não Efetivação da Doação (\%)

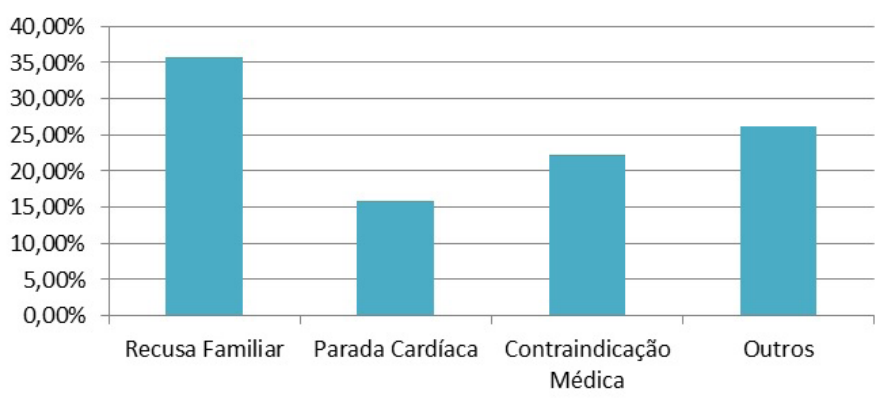

Deve-se questionar, portanto, o que poderia ser feito de diferente. Seria, talvez, responsabilidade de um órgão supremo como o Ministério da Saúde? Seria necessária uma quantidade massiva de investimento público? Tendo o Brasil dimensões continentais com diferenças socioeconômicas gritantes, qualquer projeto que exigisse escalabilidade nacional e verba pública elevada já seria suficiente para fadá-lo ao fracasso. Desta forma, propõe-se que um sistema eficiente de informação da população deve ter as seguintes características: ser de fácil execução e formação de agentes, ser barato (para quem fornece e recebe a informação, e para quem prove o treinamento dos formadores) e que abranja boa amostra populacional, sem distinção de classe social, sexo e nível de instrução.

Para a construção dessa ideia, foi selecionado o ambiente do Curso de Formação de Condutores (CFC), parte do processo de habilitação automotiva, que reúne as características expostas acima: quase toda a população numa certa faixa etária adequada (majoritariamente início da idade adulta) frequenta esse ambiente de maneira mandatória, independentemente de outras características que normalmente estratificariam a população, como instituição de saúde ou educação que frequentam, por exemplo. Vale ressaltar também que o tema morte encefálica justifica-se por si só dentro do tema acidentes de trânsito fatais e trauma, sendo um excelente gancho para a introdução da questão da doação de órgãos.

Além disso, aqueles que participam do curso e a instituição que o fornece não teriam nenhum custo extra; uma vez realizado o treinamento do instrutor responsável, a informação poderá ser passada repetidas vezes, sem necessidade de cursos de atualização. Pensou-se também na inclusão de algumas informações pertinentes ao tema no material já fornecido no CFC, o que teria um custo muito baixo.

O próximo desafio seria a formação dos instrutores do CFC. Nesse ponto, poderiam ser envolvidas unidades de saúde de referência, bem como hospitais ligados a universidades, em que poderiam estar envolvidas, inclusive, ligas acadêmicas e alunos de graduação. Reduzindo as aulas ao essencial, poderiam ser ministradas palestras de no máximo duas horas, incluindo conceitos básicos sobre morte encefálica, processo de doação de órgão, organização da fila de transplante e funcionamento das centrais de transplante, como esquematizado na figura 2, que podem ser facilmente repassadas ao longo do curso.

Figura 2-Equema do processo de doação deórgãos=principais pontosa seremesclarecidosà população.

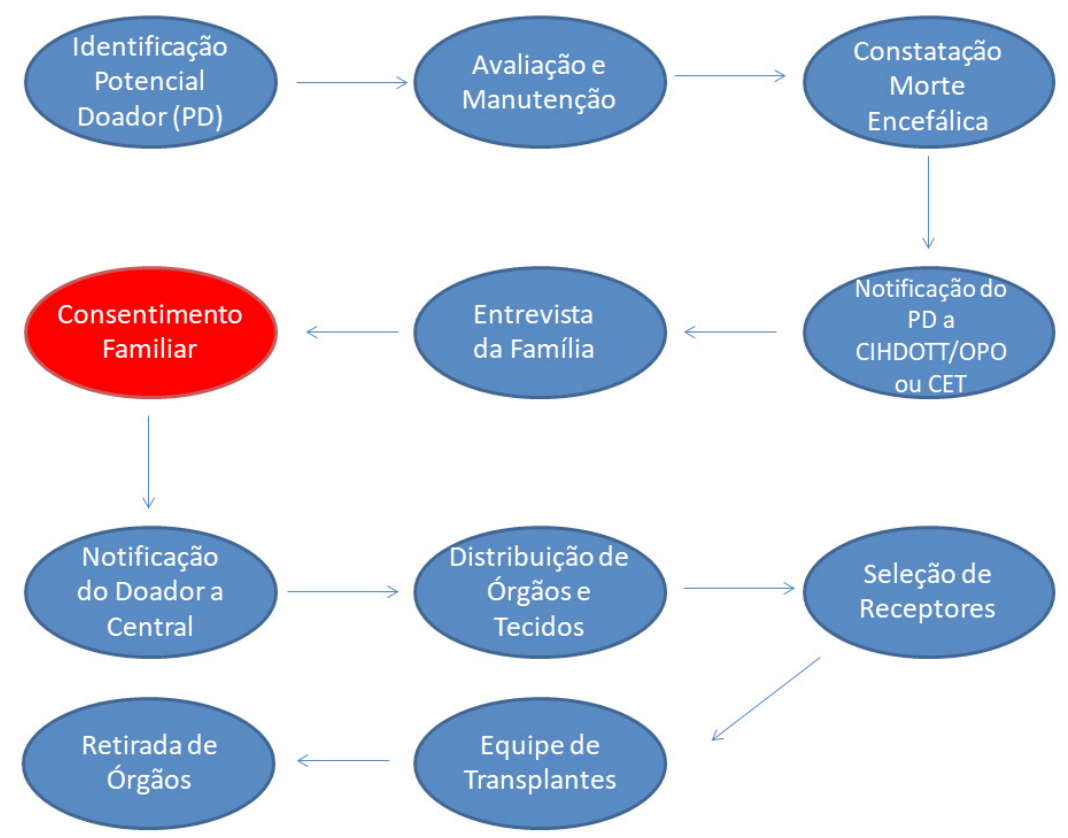


Ciente disso, tal proposta está em vias de ser colocada em prática na cidade de Ribeirão Preto, interior de São Paulo com quase 700 mil habitantes, como uma forma de testar a efetividade da proposta descrita. A metodologia será transformada num projeto de lei e levada para a Câmara Municipal para receber apoio de um vereador. Tal procedimento será adotado em detrimento da "iniciativa popular", evitando a necessidade de reunir a assinatura de $5 \%$ do contingente eleitoral, agilizando a votação e a colocação da lei em prática. No caso de Ribeirão Preto, a formação será feita de maneira gratuita por meio de palestras ministradas no Hospital das Clínicas da Faculdade de Medicina de Ribeirão Preto da Universidade de São Paulo (HCFMRP USP), tanto por docentes, enfermeiras do setor de transplantes e alunos envolvidos com a Liga Acadêmica de Cirurgia e Transplante, reafirmando a importância na ação das ligas e da universidade nesses casos. ${ }^{2}$
Dessa forma, abre-se um novo horizonte no que tange à educação relacionada à doação e transplante de órgãos, partindo de uma ideia que dependa de pouco investimento e que vise o maior alcance possível. Para potencializar o sucesso do programa de transplante de órgãos no Brasil, investir em melhorar a técnica cirúrgica e ampliar o número de centros que realizam o procedimento é só uma face da questão; o maior desafio ainda reside em esclarecer a população de que a doação é perfeitamente segura e confiável, e deixar para fazê-lo no momento da morte de um ente querido é um péssimo timing.

É necessário introduzir o tema de forma maciça, persistente e continuada, com o intuito de promover a discussão no seio familiar, preparando o indivíduo para um momento de decisão. Não há nada mais custoefetivo que educação, ainda mais quando realizada na modalidade de atenção primária.

\section{ABSTRACT}

The article aims to offer a new alternative to the issue of organ donation. Approximately $42 \%$ of donations that are not effective are due to family refusal, and this is largely due to the lack of knowledge regarding concepts such as brain death, organ donation process and how the list of recipients works. It is suggested the inclusion of classes on these topics during the Driver Training Course (CFC), and training for instructors offered by universities and public health units, since it has a low establishment cost. The proposal will be taken to the town hall, transformed into a law bill and voted, to be implemented in the city of Ribeirão Preto with support by the Ribeirão Preto Medical School (FMRP) and the Academic League of Surgery and Transplantation of FMRP, reminding the importance of academic institutions in the donation process.

Keywords: Tissue and Organ Procurement; Transplantation; Tissue Donors; Education, Medical; Legislation as Topic.

\section{REFERÊNCIAS}

1 Associação Brasileira de Transplante de Órgãos (ABTO). Registro Brasileiro de Transplantes (RBT). São Paulo, 2017.
2 Graf C, Silva O. Doação de órgãos e transplante: um binômio a ser otimizado. RMRP [Internet]. 30out.2017; 50(5):345-8. Available from: http://www.revistas.usp.br/rmrp/article/view/143210

\section{AGRADECIMENTOS}

Agradecimentos ao departamento de Cirurgia e Anatomia da FMRP, em especial a equipe de Transplante de Fígado, que desde 2001 constrói trajetória inspiradora dentro do HCFMRP USP, e à Liga Acadêmica de Cirurgia e Transplante da FMRP, que se encarrega de trabalhar junto ao corpo discente e população para estimular a doação de órgãos. 